\title{
The Unsuitability of the Uridine Incorporation Assay for the Measurement of Phagocytosis of Escherichia coli
}

\author{
By ALI FAZELI AND LEE RICHARDS* \\ Department of Microbiology and Isotope Unit, Queen Elizabeth College, Campden Hill Road, \\ Kensington, London W8 $7 A H, U . K$.
}

(Received 23 May 1983)

\begin{abstract}
The uridine incorporation technique for assaying phagocytosis is based on the fact that polymorphonuclear leucocytes are impermeable to labelled uridine, and therefore ingested bacteria inside phagocytic vacuoles will be unable to take it up. Extracellular bacteria, including those adherent to the phagocytic cell surface, can do so however. Differences in uptake between bacteria alone and in the presence of phagocytic cells can be used to measure ingestion. The present paper describes the application of this technique to Escherichia coli O-86 as the test organism. It appears that with this test species, the method is unsuccessful, because exposure of the non-ingested bacteria to some soluble product of the triggered polymorphonuclear leucocytes causes a large increase in their uridine uptake rates, over that of the control bacteria. The nature of the product responsible is unknown. It is unconnected with change in the $\mathrm{pH}$ of the medium, is heat stable, and is only produced by polymorphonuclear leucocytes which are actively phagocytosing. It may be that a release of phagolysosome contents is responsible.
\end{abstract}

\section{INTRODUCTION}

An alternative technique to the classical ingestion test for assaying phagocytosis, which is able to discriminate between intracellular and surface adherent extracellular test bacteria, was developed by Foroozanfar et al. (1976) and Yamamura et al. (1977). This assay is based on the incorporation of a labelled tracer such as thymidine or uridine, into uningested bacteria during the post-phagocytic period. A successful assay required the system to have the following properties. (a) Tracer uptake should be linearly correlated with number of test bacteria used. (b) Phagocytic cells should be impermeable to the tracer, so that surviving intracellular bacteria are unable to take it up. Comparison of incorporation in the presence with that in the absence of phagocytic cells would then allow an estimate of phagocytic ingestion.

The technique has been used successfully with Staphylococcus aureus and rabbit leucocytes (Lam \& Mathison, 1979) and the yeasts Candida albicans (Yamamura et al., 1977) and Torulopsis glabrata (Thong \& Ferrante, 1977). Braconier \& Odeberg (1979) modified the technique to enable both phagocytosis and intracellular killing of $S$. aureus and Streptococcus pneumoniae to be assayed simultaneously. They combined incorporation measurements with total bacterial viable counts following recovery of viable intracellular bacteria from phagocytic cells by osmotic lysis. Although an increase in thymidine incorporation by bacteria exposed to either intact granulocytes, or extracts of such cells was observed, it was claimed that the procedure could be made very reliable by decreasing the number of phagocytic cells used.

Similarly Bridges et al. (1970) also modified the procedure to allow simultaneous estimation of ingestion and killing of $C$. albicans by measurements in the presence and absence of sodium deoxycholate, which disrupts the phagocytic cells permitting viable intracellular yeasts to take up the extracellular radiolabelled uridine provided. 
In the present paper, the validity of the technique of Foroozanfar (1976) was investigated using Escherichia coli as the test organism to assay phagocytosis by human polymorphonuclear leucocytes (PMNL).

\section{METHODS}

Bacteria and polymorphonuclear leukocytes. Escherichia coli 0-86 was obtained from St Stephen's Hospital, Fulham Road, London and maintained on nutrient agar slopes, and grown for experiments on Tryptic Soy broth at $37^{\circ} \mathrm{C}$. Cells were harvested in early-stationary phase, and washed in Hank's balanced salts solution (HBSS) then opsonized by $30 \mathrm{~min}$ incubation at $37^{\circ} \mathrm{C}$ in $1 \mathrm{ml}$ human serum followed by washing and resuspension in HBSS.

PMNL suspensions in HBSS were prepared by a modification of the method of Boyum (1968). Preservative-free heparin was added to $20 \mathrm{ml}$ blood to a concentration of $10 \mu 1 \mathrm{ml}^{-1}$. One part of $6 \%(\mathrm{w} / \mathrm{v})$ dextran in saline was added to four parts of blood by volume, and after $30 \mathrm{~min}$ the leucocyte-rich plasma was separated by centrifuging at $300 \mathrm{~g}$ for $7 \mathrm{~min}$. After resuspension in $4 \mathrm{ml} \mathrm{HBSS}$, pellets were layered on to $3 \mathrm{ml}$ Ficoll-Paque, and centrifuged for $30 \mathrm{~min}$ at $400 \mathrm{~g}$. The PMNL containing pellet was resuspended in $0.83 \%$ Tris buffered ammonium chloride, pH 7.2 for hypotonic lysis of residual erythrocytes, and after 5 min the pellet washed twice in HBSS and adjusted to the required cell density. Further details of the procedure are given in Fazeli (1982).

Phagocytosis assay by uptake of tritiated uridine. Unless otherwise stated, assays were set up in sterile siliconized screw-capped glass bottles. Incubation mixtures containing human PMNL from healthy volunteers and preopsonized $E$. coli in HBSS were incubated on a shaking incubator at $37^{\circ} \mathrm{C}$. Similar control tubes lacking either bacteria or PMNL were also incubated. After allowing phagocytosis to proceed for 20 min, further incubation for $60 \mathrm{~min}$ with $1 \mu \mathrm{Ci}\left[5,6^{-3} \mathrm{H}\right]$ uridine $\mathrm{ml}^{-1}\left(37 \mathrm{kBq} \mathrm{ml}^{-1} ; 27 \mathrm{pmol} \mathrm{ml}^{-1}\right)$ was carried out to allow incorporation of the radiolabel. Samples $(1 \mathrm{ml})$ were removed at timed intervals during this incubation, and PMNL and bacteria were recovered on cellulose nitrate membrane filters $(0.45 \mu \mathrm{m}$ pore-size, $2.5 \mathrm{~cm}$ diameter $)$ in a vacuum filtration manifold. Both the filters and the filtrates were saved, and the filters washed with $20 \mathrm{ml}$ HBSS, and dissolved in $5 \mathrm{ml}$ Bray's scintillation fluid (Bray, 1960). Samples $(500 \mu \mathrm{l})$ of the filtrates were dissolved in $10 \mathrm{ml}$ Bray's fluid and radioactivity was quantitated using either a Beckman LS233 liquid scintillation counter (at $8^{\circ} \mathrm{C}$ ), or a Packard $460 \mathrm{CD}$ liquid scintillation counter at room temperature. Samples were counted twice for $10 \mathrm{~min}$ each, and observed count rates corrected for sample quenching by the external standard method.

Uridine permeability of $E$. coli exposed to resting or phagocytosing PMNL. Mixtures of PMNL and bacteria, or PMNL alone were incubated for $20 \mathrm{~min}$ at $37^{\circ} \mathrm{C}$, then centrifuged at $10000 \mathrm{~g}$ and room temperature for $10 \mathrm{~min}$ in a Micro-angle centrifuge (Baird \& Tatlock, London). Supernatants were mixed with pellets of opsonized bacteria, and after $20 \mathrm{~min}$ at $37^{\circ} \mathrm{C}$ the mixtures were further incubated with $\left[{ }^{3} \mathrm{H}\right.$ ]uridine and treated as described previously.

\section{RESULTS}

\section{Uridine incorporation by $E$. coli $0-86$}

Varying concentrations of opsonized bacteria in a total volume of $2 \mathrm{ml} \mathrm{HBSS}$ were mixed with $\left[{ }^{3} \mathrm{H}\right]$ uridine at $37^{\circ} \mathrm{C}$ for $60 \mathrm{~min}$, and at intervals samples were taken and processed as described in Methods.

Uridine incorporation after $30 \mathrm{~min}$ incubation, as a function of bacterial numbers is shown in Fig. 1. The uridine incorporation per cell by opsonized $E$. coli after $30 \mathrm{~min}$ incubation varied between 0.106 and 0.128 amol. The average concentration factor (intracellular concentration divided by extracellular concentration) inside the bacterial cells was $25.6 \times 10^{3}$ on the assumption of an internal bacterial cell volume of $0.78 \mu \mathrm{m}^{3}$ all assumed to be available to the intracellular uridine, and assuming insignificant consumption of the uridine by the metabolism or for macromolecular synthesis during the incorporation period.

Uptake by the heat-killed bacteria $\left(56^{\circ} \mathrm{C}\right.$ for $90 \mathrm{~min}$ ) was only about $1 \%$ of that by the living bacteria in the same time (Fig. 2).

\section{Uridine uptake by $E$. coli in a phagocytosis mixture}

Phagocytic mixtures containing $5 \times 10^{6} \mathrm{PMNL}$ and $5 \times 10^{7}$ c.f.u. E. coli O-86 in total volume of $2.5 \mathrm{ml}$ HBSS were incubated in duplicate. After $20 \mathrm{~min}$ at $37^{\circ} \mathrm{C}$ one tube had $\left[{ }^{3} \mathrm{H}\right]-$ uridine added as described above, and the other was centrifuged at $300 \mathrm{~g}$ for $5 \mathrm{~min}$, and the pellet washed twice with HBSS to remove unattached extracellular bacteria, resuspended in the original volume of HBSS, then reincubated with $\left[{ }^{3} \mathrm{H}\right]$ uridine as before. Control mixtures of 


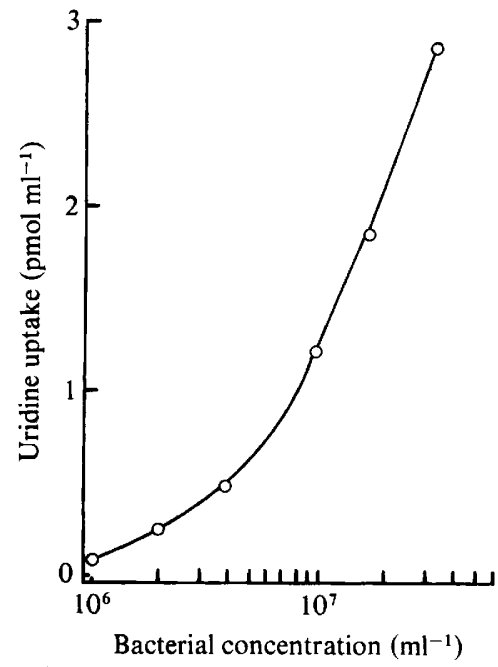

Fig. 1. Incorporation of $\left[{ }^{3} \mathrm{H}\right]$ uridine by varying numbers of $E$. coli $\mathrm{O}-86$ after 30 min incubation at $37{ }^{\circ} \mathrm{C}$. Stationary phase opsonized $E$. coli were resuspended in HBSS with labelled uridine at $20 \mathrm{nM}$. Samples were withdrawn at timed intervals, filtered and washed. Filter and filtrate incorporated radioactivity was measured as described in the text.

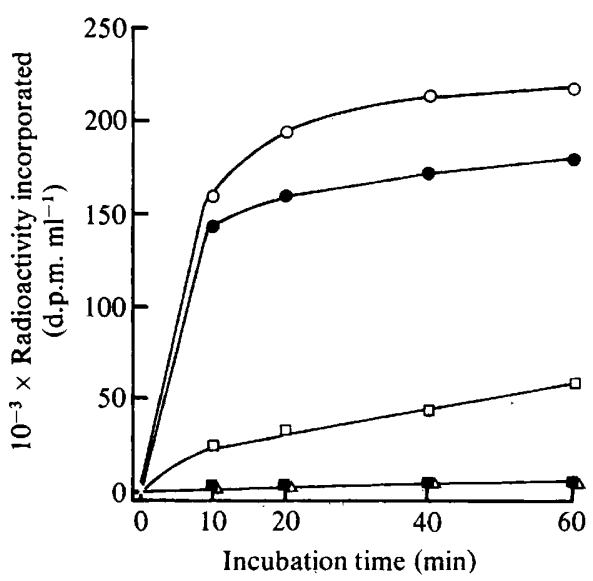

Fig. 2

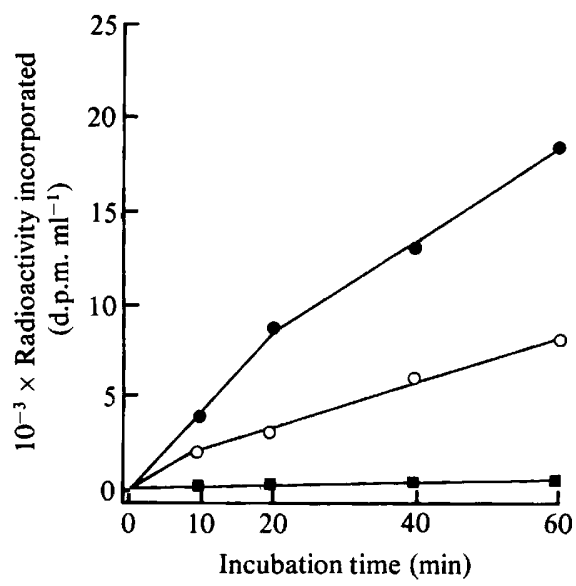

Fig. 3

Fig. 2. Incorporation of $\left[{ }^{3} \mathrm{H}\right]$ uridine into a phagocytic mixture. Time course of incorporation of uridine at $20 \mathrm{nM}$ into a mixture containing $5 \times 10^{6} \mathrm{PMNL} \mathrm{ml}^{-1}$ and $5 \times 10^{7} \mathrm{E}$. coli O-86 ml-1 $(\mathrm{O})$, opsonized E. coli alone (O), PMNL alone ( $\square$ ), E. coli attached to the PMNL surface but not ingested ( $\square$ ), and an equal number of heat killed $E$. coli $(\triangle)$.

Fig. 3. $\left[{ }^{3} \mathrm{H}\right]$ uridine incorporation by phagocytosis mixture. $\left[{ }^{3} \mathrm{H}\right]$ Uridine incorporation by $5 \times 10^{7} S$.

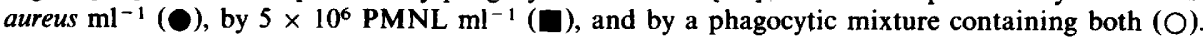
Experimental conditions identical to those in which $E$. coli was used as test organism.

either bacteria alone or PMNL alone were treated similarly (Fig. 2). Incorporation into bacteria in phagocytic mixtures was always higher than that into the bacteria alone, although the PMNL were impermeable to the labelled uridine. There was a variation in uridine uptake by PMNL observed with PMNL from different donor individuals, but such uptake was always insignificant compared with that by the bacteria. Uptake by PMNL plus associated extra- 


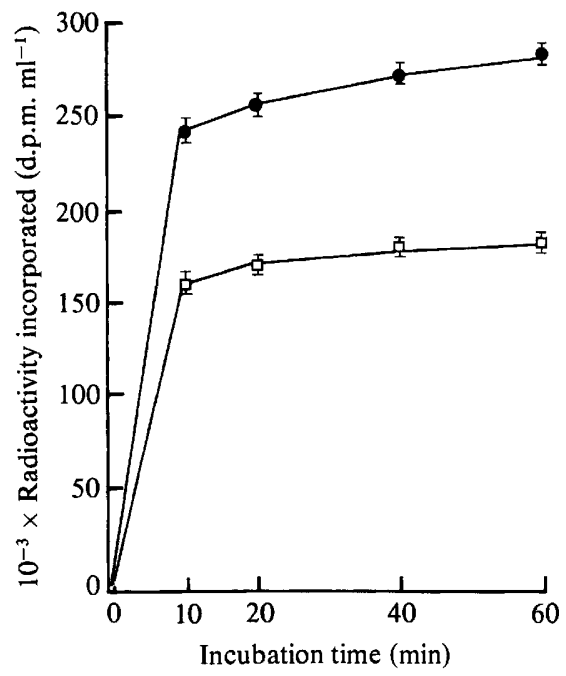

Fig. 4

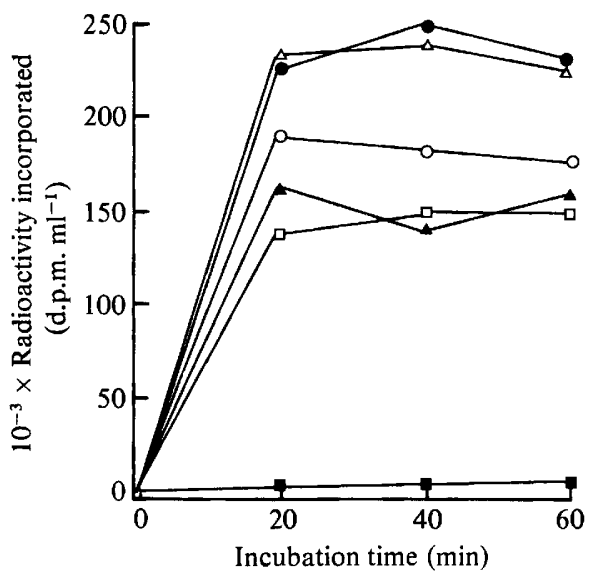

Fig. 5

Fig. 4. Effect of supernatant from phagocytosis mixture on $\left[{ }^{3} \mathrm{H}\right]$ uridine uptake by $E$. coli. Incorporation by $E$. coli $\mathrm{O}-86\left(5 \times 10^{7}\right)$ suspended in fresh $\mathrm{HBSS}(\square)$, or the supernatant from a phagocytosis mixture (O). Each point is the mean of five experiments, the error bars show the S.E.

Fig. 5. Influence of the suspending medium on $\left[{ }^{3} \mathrm{H}\right]$ uridine uptake by $E$. coli $\mathrm{O}-86$. Uptake by $5 \times 10^{7}$ stationary phase opsonized $E$. coli in HBSS containing $1 \mu \mathrm{Ci}\left[{ }^{3} \mathrm{H}\right]$ uridine $(20 \mathrm{nM})$ in a total volume of $2 \mathrm{ml}$. Assay mixtures were PMNL alone ( $\square$ ), bacteria plus PMNL which had been incubated $20 \mathrm{~min}$ before addition of uridine $(O)$, and bacteria alone suspended in fresh HBSS $(\square)$, supernatant from resting PMNL (A), supernatant from phagocytosing PMNL ( $)$ ), and heat-treated supernatant from phagocytosing PMNL $(\Delta)$.

cellular bacteria was also higher than that by PMNL alone, and this is attributed to uptake by the adherent bacteria on the PMNL surface.

\section{Uridine incorporation by Staphylococcus aureus $C-18$ in the phagocytic system}

As a control for the assay procedure, an identical set of experiments was carried out using $S$. aureus C-18 as the test organism. This species has previously been used successfully in this type of assay (Lam \& Mathison, 1979).

The result is shown in Fig. 3, from which it can be seen that the uptake by phagocytic mixtures was substantially less than that by bacteria alone, as would be expected. The amount of incorporation by a given number of $S$. aureus was also considerably less than that by a corresponding number of $E$. coli in an identical experiment.

\section{Uridine incorporation by uningested E. coli exposed to PMNL}

To investigate the influence of exposure to granulocytes on the permeability of $E$. coli to uridine, $5 \times 10^{7}$ stationary phase opsonized bacteria were suspended in cell-free supernatant from a phagocytosis mixture as described above. The incorporation of labelled uridine by such a suspension was greatly increased compared with the incorporation by a corresponding suspension in unused HBSS (Fig. 4). Heating of the HBSS supernatant from phagocytosis mixtures to $56^{\circ} \mathrm{C}$ for $60 \mathrm{~min}$ produced no loss of the ability to increase the bacterial permeability to uridine (Fig. 5), and the same effect on $E$. coli permeability was also produced by supernatants from phagocytosis mixtures in which PMNL were ingesting $S$. aureus $\mathrm{C}-18$.

The supernatants from resting PMNL suspensions after $30 \mathrm{~min}$ incubation at $37^{\circ} \mathrm{C}$ caused no 
such enhancement of uridine uptake (Fig. 5), thus the effect may be attributed to some soluble extracellular, heat-stable product of the triggered phagocyte.

\section{DISCUSSION}

The uridine (or thymidine) incorporation assay has been used with a variety of test organisms. The present study was undertaken to assess the validity of the technique for phagocytosis of $E$. coli. However, the degree of incorporation of radiolabelled uridine into bacteria which had been exposed to triggered PMNL far exceeded that by unexposed $E$. coli due presumably to the action of some product of the active PMNL metabolism, and was independent of the bacteria : PMNL ratios (data not shown). In contrast, using $S$. aureus as the test organism in an identical series of experiments, the technique worked well, and allowed an estimate of ingestion from the reduction in uptake in the presence of phagocytic cells. It thus appears that the technique cannot be used as it stands with $E$. coli as the test organism, and further, that it is necessary to test, when using the technique for the first time with a new species, that a similar effect does not take place. It is possible that the assay could be modified by comparing the uptake in phagocytosis mixtures not with that by bacteria alone, but rather with the uptake by a suspension of bacteria incubated in the supernatant from an identical phagocytosis mixture. However, since the uningested bacteria in the mixture are only affected by a product of triggered PMNL, and not of resting cells, presumably the agent responsible for the effect is only produced from the start of the incubation, and is changing in concentration during the assay. It is thus difficult to see how a matched control could be created to compare with the uptake by the mixture.

The effect on uptake rates cannot be attributed to growth of the bacteria, since the $E$. coli used were at stationary phase, and exhibited no growth at least for $3 \mathrm{~h}$ in this medium (Fazeli, 1982). An unequivocal increase in the rate of uptake of $\left[{ }^{3} \mathrm{H}\right]$ uridine by $E$. coli was produced by exposure to phagocytosing PMNL, but not by resting PMNL. Since it was possible to induce such an increase by exposure of the bacteria to the supernatant of phagocytosing PMNL alone, it is clear that a soluble product of the metabolism of triggered PMNL is responsible. The responsible product appears to be produced (and to be active against $E$. coli) irrespective of the nature of the test organism used to trigger the PMNL, that is, it appears to be a general property of the phagocytic response. The agent responsible is stable to heat at $56{ }^{\circ} \mathrm{C}$ for $1 \mathrm{~h}$, which suggests that it is not a heat-labile protein. Further the effect is not one of simple alteration of the medium $\mathrm{pH}$, since there was no change in the $\mathrm{pH}$ of the medium for at least $2 \mathrm{~h}$ of phagocytosis (Fazeli, 1982).

A phagocyte-induced change in membrane permeability of Gram-negative bacteria has previously been reported using intact PMNL (Beckerdite et al., 1974), disrupted PMNL, or fractions from PMNL cells (Elsbach et al., 1974; Weiss et al., 1976) and by a combination of serum and antibiotics (Dutcher et al., 1978). The killing of E. coli by PMNL is accompanied by an increase in permeability of the bacterial envelope. This may be due to enzyme attack or degradation of structural components of the membrane by reactive species, and may take place intraphagosomally or (as must be the case here) extracellularly by release of the responsible factors into the suspending medium. Factors known to be released into the medium during phagocytosis include plasminogen activator (Granelli-Piperno et al., 1977), lysozyme and $\beta$ glucuronidase (Wright \& Malawista, 1972; Okamura et al., 1979), $N$-acetyl- $\beta$-glucosaminidase (Johnston \& Lehmeyer, 1976) lactoferrin and myeloperoxidase (Leffell \& Spitznagel, 1975), hydrogen peroxide and superoxide anion (Root et al., 1975; Hafeman \& Lucas, 1979). Weiss et al. (1976) have reported a highly purified rabbit PMNL fraction able to increase $E$. coli envelope permeability, and demonstrated that it consisted of cationic proteins and phospholipase A2 (Elsbach et al., 1979).

Phagocytic vacuole contents may be released simply as a result of cell death, or by regurgitation during phagocytosis, reverse endocytosis (Goldstein, 1976), or may be induced by complement and immunoglobulin (Henson, 1971). It is probably unlikely that the $E$.coli envelope damage results from antibody/complement action, since the effect is not observed with 
supernatants from resting PMNL and opsonized bacteria. It could be a result of the myeloperoxidase/hydrogen peroxide system however (Sips \& Hamers, 1981).

Elsbach et al. (1974) found that exposure of $E$. coli to granulocyte extracts increased the rate of incorporation of labelled precursors into RNA by more than 15-fold, and into protein and DNA about twofold. This effect took place even $30 \mathrm{~min}$ after the bacteria had lost the ability to multiply.

Thus the present results, which mean that the assay technique is not suitable for measuring phagocytosis of $E$. coli are supported by these previous observations, and it appears that an increased rate of uridine incorporation in bacteria exposed to phagocytosing PMNL results from an effect on the envelope of cells of the non-ingested population brought about by one or more reactive species released from the PMNL.

\section{REFERENCES}

Beckerdite, S., Mooney, C., Weiss, J., Franson, R. \& ELSBACH, P. (1974). Early and discrete changes in permeability of Escherichia coli and certain other Gram negative bacteria during killing by granulocytes. Journal of Experimental Medicine 140, 396409.

BoyUM, A. (1968). Isolation of leukocytes from human blood. Scandinavian Journal of Clinical Investigation 21, 1-109.

BRACONIER, J. H. \& ODEBERG, H. (1979). Evaluation of phagocytic and bactericidal activities of neutrophil granulocytes: determination of viable extracellular bacteria by their incorporation of ${ }^{14} \mathrm{C}$-leucine and ${ }^{3} \mathrm{H}$-thymidine. Scandinavian Journal of Haematology 23, 407-415.

BRAY, G, A. (1960). A simple efficient liquid scintillator for counting aqueous solutions in a liquid scintillation counter. Annals of Biochemistry 1, 279285.

Bridges, C. G., Dasilva, G., Yamamura, M. \& VALDIMARsson, H. (1980). A radiometric assay for the combined measurement of phagocytosis and intracellular killing of Candida albicans. Clinical and Experimental Immunology 42, 226-233.

DutCher, B. S., ReYNARD, A. M., Beck, M. E. \& CunninghaM, R. K. (1978). Potentiation of antibiotic bactericidal activity by normal human serum. Antimicrobial Agents and Chemotherapy 13, 820826.

Elsbach, P., Beckerdite, S., Pettis, P. \& Franson, R. (1974). Persistence of regulation of macromolecular synthesis by Escherichia coli during killing by disrupted rabbit granulocytes. Infection and Immunity 9. 663-668.

Elsbach, P., Weiss, J., Franson, R. C., Beckerdite, S, SCHNEIDER, A. \& HARRIS, L. (1979). Separation and purification of a potent bactericidal/permeability-increasing protein and a closely associated phospholipase A2 from rabbit polymorphonuclear leukocytes. Journal of Biological Chemistry 254, 11000-11009.

FAZELI, A. (1982). The ingestion and killing of Escherichia coli by polymorphonuclear leukocytes. Ph.D. thesis, University of London.

Foroozanfar, N., Aghai, Z., Ala, F. \& Hobbs, J. R. (1976). Inhibition of thymidine uptake by Staphylococci: a new method for the investigation of phagocytosis. Journal of Immunological Methods 11, 345353.
Goldstein, I. M., (1976). Polymorphonuclear leukocyte lysosomes and immune tissue injury. Progress in Allergy 20, 301-340.

Granelli-Piperno, A., Vassali, J. D. \& Beich, E. (1977). Secretion of plasminogen activator by human polymorphonuclear leukocytes: modulation by glucocorticoids and other effectors. Journal of Experimental Medicine 146, 1693-1706.

Hafeman, D. G. \& LuCAs, Z. J. (1979). Polymorphonuclear mediated, antibody dependent, cellular cytotoxicity against tumour cells: dependence on oxygen and respiratory burst. Journal of Immunology 123, 55-62.

HeNson, P. M. (1971). The immunologic release of constituents from neutrophil leukocytes. I. The role of antibody and complement on non-phagocytosable surfaces or phagocytosable particles. Journal of Immunology 107, 1535-1546.

JOHNSTON, R. B. \& LEHMEYER, J. E. (1976). Elaboration of toxic oxygen by-products by neutrophils in a model of immune complex disease. Journal of Clinical Investigation 57, 836-841.

Lam, C. \& Mathison, G. E. (1979). Phagocytosis measured as inhibition of uridine uptake: a method that distinguishes between surface adherence and ingestion. Journal of Medical Microbiology 12, 459467.

LefFell, M. S. \& SpITZNAGel, J. K. (1975). Fate of human lactoferrin and myeloperoxidase in phagocytosing human neutrophils: effects of immunoglobulin $\mathrm{G}$ subclasses and immune complexes coated on latex beads. Infection and Immunity 12, 813-820.

OKamura, N., Ishibashi, S. \& Takano, T. (1979). Evidence for bactericidal activity of polymorphonuclear leukocytes without phagocytosis. Journal of Biochemistry 86, 469-475.

Root, R. K., Metcalf, J., Oshino, N. \& Chance, B. (1975). Hydrogen peroxide release from human granulocytes during phagocytosis, I. Documentation, quantitation and some regulation factors. Journal of Clinical Investigation 55, 945-955.

SIPS, H. J. \& HAMERS, M. N. (1981). Mechanism of bactericidal action of myeloperoxidase: increased permeability of Escherichia coli cell envelope. Infection and Immunity 31, 11-16.

Thong, Y. H. \& Ferrante, A. (1977). Phagocytosis and killing of Torulopsis glabrata by human neutrophils. International Review of Science: Medical Science 5, 482. 
Weiss, J., Franson, R. C., Schmeider, K. \& Elsbach, P. (1976). Reversible envelope effects during and after killing of Escherichia coli W by a highly purified rabbit polymorphonuclear leukocyte fraction. Biochimica et biophysica acta 436, 154-169.

Wright, D. G. \& Malawista, S. E. (1972). The mobilisation and extracellular release of granular enzymes from human leukocytes during phagocytosis. Journal of Cell Biology 53, 788-797.

Yamamura, M., Boler, J. Valdimarsson, H. (1977).

Phagocytosis measured as inhibition of uridine uptake by Candida albicans. Journal of Immunological Methods 14, 19-24. 